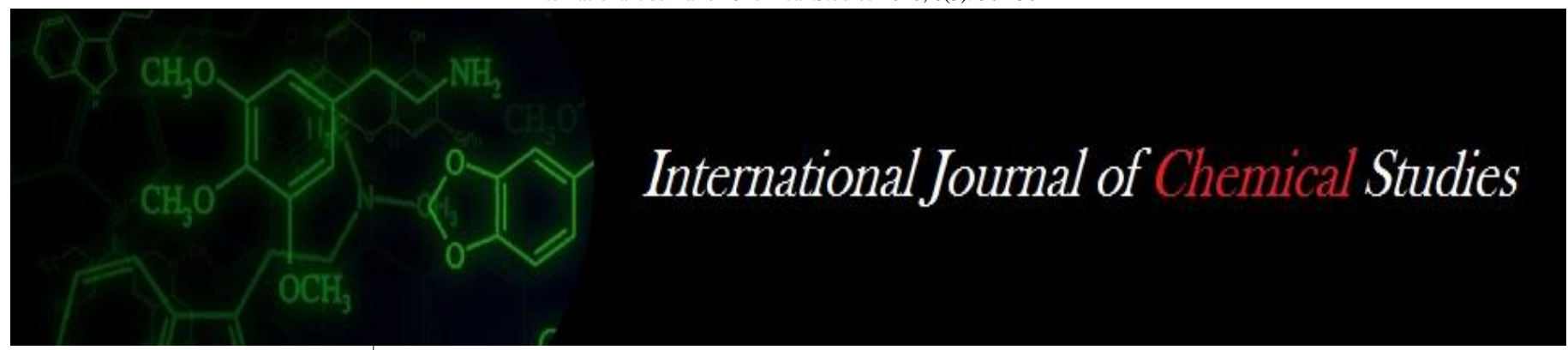

P-ISSN: 2349-8528

E-ISSN: 2321-4902

www.chemijournal.com

IJCS 2020; 8(3): 501-504

(C) 2020 IJCS

Received: 11-03-2020

Accepted: 13-04-2020

\section{A. Rajkala}

Research Scolar Department of

Extension Education, Tamil

Nadu Agricultural University,

Coimbatore, Tamil Nadu, India

\section{R. Jansirani}

Professor (Agrl. Extension)

Department Sustainable Organic

Agriculture, Tamil Nadu

Agricultural University,

Coimbatore, Tamil Nadu, India

\section{R. Arunachalam}

Professor (Agrl. Extension.)

Department of Agricultural

Extension \& Rural Sociology

Tamil Nadu Agricultural

University, Coimbatore, Tamil

Nadu, India
Corresponding Author:

A Rajkala

Research Scolar Department of

Extension Education, Tamil

Nadu Agricultural University,

Coimbatore, Tamil Nadu, India

\section{Assess the effectiveness of training module for sustainable Cashewnut cultivation in Tiruchirappalli region of Tamil Nadu}

\author{
A. Rajkala, R. Jansirani and R. Arunachalam
}

DOI: $\underline{\text { https://doi.org/10.22271/chemi.2020.v8.i3f.9258 }}$

\begin{abstract}
Cashewnut is a native of Eastern Brazil introduced to India just as other commercial crops like Rubber, Coffee, and Tea. In Tamil Nadu cashew is the one of the major plantation crop, which is being grown under 91058 ha. Cashew production is 57988 MT and productivity is 0.64 MT per hectare. In Tamil Nadu introduced various development programmes in cashew over the period. But the production and productivity are low only. It may be due to lack of knowledge and adoption behavior among the farmers to increases the above domains, the present study on developing Training Module for Sustainable Cashewnut cultivation. The study was conducted at Ariyalur District of Tamil Nadu with sample size of 180. Multiple randomized group design was used in this experimental study. Three training modules were tested/assessed among the selected respondents by using various dimensions of training methods. Well - structured and pre -tested questionnaire was used for evaluating knowledge gain and symbolic adoption behavior of the farmers. It was found that lecture supported with Video + Demonstration + Interaction with successful farmer's experiences sharing during field visit were effective in terms of knowledge gain and symbolic adoption in Cashewnut. The developed training module was proposed to the farming community for achieving sustainable Cashewnut cultivation in the region of Tiruchirappalli.
\end{abstract}

Keywords: Training module, knowledge gain, symbolic adoption, sustainable, cashewnut cultivation

\section{Introduction}

Cashewnut (Anacardium occidentale L.) belongs to the order Sapindales, family Anacardiaceae and genus Anacardium. Cashewnut a native of Eastern Brazil introduced to India just as other commercial crops like Rubber, Coffee, and Tea by the Portuguese nearly five centuries back. The first introduction of cashew in India was made in Goa from where it spread to other parts of the country. In the beginning it was mainly considered as a crop for afforestation and soil binding to check erosions. India was the first country to hit the world market with cashew kernels and it was she who pioneered cashew processing as an industry. The raw cashew nuts collected from the growing areas are moved to the factories for processing.

In 2017, global production of cashew nuts as the kernel was 3,971,046 tones, led by Vietnam, India and CôtedIvoire with 22.00 per cent, 19.00 per cent, and 18.00 per cent of the world's total respectively. World's largest producer of Cashewnut (kernels) Vietnam (863060 MT), India (745000 MT), CotedIvoire (711000 MT) (Source: FAOSTAT of the United Nations, 2017). In India, cashew is grown in an area of 1.02 million hectare, with a productivity of 706 $\mathrm{kg} / \mathrm{ha}$. The major cashew growing Indian states are Maharashtra, Andhra Pradesh, Orissa, Kerala, and Karnataka. Approximate raw cashew nut requirement of the country is estimated to be at 4-5 million metric tons or more by 2050 .

In Tamil Nadu cashew is the one of the major plantation crop, which is being grown under 91058 ha. Cashew production is 57988 MT and productivity is 0.64 MT per hectare. The major cashew growing districts of Tamil Nadu are Ariyalur, Cuddalore, Villupuram, Pudukottai, Sivagangai and Theni. (Source: Department of Horticulture and Plantation, Chennai). Among the different cashew growing districts in Tamil Nadu, Ariyalur (31.4\%), Cuddalore $(30.2 \%)$ and Pudukkottai $(8.5 \%)$ were the major cashew growing districts accounting for about 70 per cent of the total area. 
Cuddalore district ranked first in terms of cashew production with 24,302 tones (47\%) and had the highest cashew productivity of $810 \mathrm{~kg}$ / ha among cashew growing districts in the state (Loganathan and Chandrasekaran, 2013) ${ }^{[4]}$.

Though the area under Cashewnut cultivation is high in Ariyalur District, the productivity level is up to $400 \mathrm{~kg} / \mathrm{ha}$. The reasons for shortfall in productivity are old senile plantation, less adoption of improved varieties, use of seedlings rather grafts and other venue in adoption of ideal practices. Only 40 percent of the technology has been adopted by the farmers, other 60 per cent of the recommended technologies have not been adopted so far due to various reasons. Though we have implemented lot of training programmes in this line, we could not achieve the result. Hence this condition necessities formulating appropriate training module relevant to present situation to impart knowledge level and symbolic adoption in Cashewnut cultivation.

\section{Methodology}

Ariyalur District of Tamil Nadu was purposively selected for this experimental study. A sample of 180 respondents $(60$ respondents/block) from Andimadam, Sendurai and Jayankondam block were selected based on random sampling method. Treatments were selected based on the discussion of KVK scientist and stakeholders. There were three treatments and each was replicated thrice.

Treatment $1(\mathrm{TM} 1)=$ Lecture with Poster + Demonstration,
Treatment $2($ TM 2$)=$ Lecture with Slides + Demonstration + Discussion Forum,

Treatment $3($ TM 3$)=$ Lecture with Video + Demonstration + Interaction with successful farmers and their experience sharing during field visit

In each block, three training modules were assigned to selected farmers in this experiment. Before - After technique of measurement was adopted to find out the effectiveness of the training module in terms of knowledge gain and symbolic adoption. Based on this methodology, the results were obtained and the findings are discussed by using appropriate statistical analysis. The selected farmers were replicated in the following manner.

\begin{tabular}{|c|c|c|c|}
\hline TM 1 & $\mathrm{t}_{1} \mathrm{~A}_{1}$ & $\mathrm{t}_{2} \mathrm{C}_{2}$ & $\mathrm{t}_{3} \mathrm{~B}_{3}$ \\
\hline TM 2 & $\mathrm{t}_{3} \mathrm{C}_{3}$ & $\mathrm{t}_{1} \mathrm{C}_{1}$ & $\mathrm{t}_{2} \mathrm{~B}_{2}$ \\
\hline TM 3 & $\mathrm{t}_{1} \mathrm{~B}_{1}$ & $\mathrm{t}_{3} \mathrm{~A}_{3}$ & $\mathrm{t}_{2} \mathrm{~A}_{2}$ \\
\hline
\end{tabular}

$\mathrm{t}_{1}=$ Andimadam block,

$\mathrm{t}_{2}=$ Sendurai block

$\mathrm{t}_{3}=$ Jayankondam block

$A_{1}$ to $A_{3}=$ First group of 60 respondents $(3$ replications of 20 nos.each) drawn randomly from the selected block

$B_{1}$ to $B_{3}=$ Second group of 60 respondents ( 3 replications of 20 nos.each) drawn randomly from the selected block

$\mathrm{C}_{1}$ to $\mathrm{C}_{3}=$ Third group of 60 respondents ( 3 replications of 20 nos.each) drawn randomly from the selected block

\begin{tabular}{|c|c|c|c|c|c|}
\hline $\mathrm{A}_{1}, \mathrm{C}_{2}, \mathrm{~B}_{3}$ & $t_{1}$ & $\mathrm{~K}$ & $\mathrm{TM} 1 \rightarrow$ & $\mathrm{K}_{1}$ & SA1 $(20+20+20=60$ respondents $)$ \\
\hline $\mathrm{C}_{3}, \mathrm{C}_{1}, \mathrm{~B}_{2}$ & $\mathrm{t}_{2}$ & $\mathrm{~K}$ & TM25 & $\mathrm{K}_{2}$ & SA2 $(20+20+20=60$ respondents $)$ \\
\hline $\mathrm{B}_{1}, \mathrm{~A}_{3}, \mathrm{~A}_{2}$ & $\mathrm{t}_{3}$ & $\mathrm{~K}$ & TM13 & $\mathrm{K}_{3}$ & SA3 $(20+20+20=60$ respondents $)$ \\
\hline & & & & & Total -180 \\
\hline
\end{tabular}

Where,

$\mathrm{K}=$ Pre - exposure

$\mathrm{K} 1$ to $\mathrm{K} 3$ = Post exposure knowledge level

$\mathrm{SA}_{1}$ to $\mathrm{SA}_{3}=$ immediate post exposure symbolic adoption behaviour

After selecting the subjects for each treatment, their initial knowledge level and other data regarding independent variable were collected. Then the subjects were exposed to the subject matter (Knowledge level) through different treatments. The selected training modules were employed in Tamil version. Immediately after exposure, the subjects were allowed to participate in the discussion forum with the trainer. This session was followed by the assessment of knowledge gain by the subjects. The mean knowledge gain of subjects for each treatments was compared by applying analysis of variance techniques to draw suitable inferences. After exposure of the subjects to the treatments pertaining to the knowledge gain, the subjects were assessed for the symbolic adoption behaviour.

\section{Results and Discussion \\ Relative effectiveness of different treatments in terms of knowledge gain}

Analysis of variance techniques was applied to find out the relative effectiveness of three different treatments in terms of knowledge gain and the results are presented in Table 1.

Table 1: Analysis of variance of Cashewnut growers' knowledge gain between the treatments $(n=180)$

\begin{tabular}{|c|c|c|c|c|}
\hline Source of variance & Degree of freedom & Sum of square & Mean square & F \\
\hline Treatment & 2 & 386.478 & 193.239 & $39.23^{* *}$ \\
\hline Error & 177 & 871.833 & 4.926 & \\
\hline Total & 179 & 1258.311 & & \\
\hline
\end{tabular}

It is evident from Table 1 that there was significant difference in the effectiveness of the treatments in imparting knowledge as indicated by the significant $F$ value at 1.00 per cent level. The relative effectiveness of the three treatments in respect of knowledge gain showed significant difference. The mean scores of the treatments were found to be in the order of

$\begin{array}{lll}\text { TM 1 } & \text { TM 2 } & \text { TM 3 } \\ \underline{9.53} & \underline{11.38} & \underline{16.13}\end{array}$

The difference of mean score is 4.75.All the three treatments were effective, but distinctly different in terms of imparting knowledge on Cashewnut technologies. It could be observed that Lecture with Video + Demonstration + Interaction with successful farmers and their experience sharing during field visit (TM 3) was found to be the effective and superior one of transfer the knowledge followed by Lecture with Slides + Demonstration + Discussion Forum(TM 2). Lecture with 
Flashcard + Demonstration was found to be least effective in infusing knowledge among respondents.

TM 3 was found to be the most effective module compared to that TM 2 and TM 1. TM3 is a combination of four methods, which included projected and non - projected visual aids. In addition, the involvement of farmers in presentation of subjects and variation in teaching aids used, might have reduced boredom and fatigue, and increased the motivation and receptiveness of the subject to the idea being presented. The change in the learning situation created by combination of aids would have also contributed greatly to the knowledge gain, this might be due to the reason of the above treatments imparting the skill to the farmers systematically and employing local authentic person in how to do practices and convince the farmers with their scientific knowledge.The similar finding was observed by Selvaraj (1981) and Sriram (2000) ${ }^{[7]}$ who reported that use of combination of extension education methods were found to be effective in imparting knowledge gain.

\section{Relative effectiveness of the treatments in terms of symbolic adoption}

The relative effectiveness of three different treatments in terms of symbolic adoption behaviour was found through analysis of variance test and the results are presented in Table 2 .

Table 2: Analysis of variance of Cashewnut growers' symbolic adoption behaviour between the treatments $(\mathrm{n}=180)$

\begin{tabular}{|c|c|c|c|c|}
\hline Source of variance & Degree of freedom & Sum of square & Mean square & F \\
\hline Treatment & 2 & 989.100 & 494.500 & $39.86^{* *}$ \\
\hline Error & 177 & 2195.850 & 12.406 & \\
\hline Total & 179 & 3184.950 & & \\
\hline
\end{tabular}

** Significant at 0.01 level

The above table that the significant $\mathrm{F}$ value indicates that there was significant difference between the treatments in influencing the symbolic adoption behaviour of cashewnut technologies among the cashew growers. The mean scores of the three treatments with respect to symbolic adoption behaviour represented in the order of

$\begin{array}{lll}\text { TM 1 } & \text { TM 2 } & \text { TM 3 } \\ \underline{8.53} & \underline{10.78} & \underline{14.23}\end{array}$

From the above results, it could be observed that TM3 had the highest symbolic adoption score followed by the treatments TM2 and TM1 among the cashewnut growers. The treatment TM3 was significantly superior to that of TM2 but it was on par with the treatment TM1 in respect of its effectiveness in terms of symbolic adoption. Similarly the treatment TM2 was found to be effective among these subjects in terms of symbolic adoption behaviour than treatment TM1.

Lecture with Slides + Demonstration + Discussion Forum (TM2) which included Demonstration which has drawn the attention of the farming community and changed their knowledge behaviour. Likewise, treatment TM3 Lecture with Video + Demonstration + Interaction with successful farmers and their experience sharing during field visit TM3 among that successful farmers interaction is very useful for changing the attitude of farmers. This might be the possible reason for treatment TM2and TM3 for their effectiveness in imparting knowledge to the cultivators.

Its concluded that the treatment Lecture with Slides + Demonstration + Discussion Forum (TM2) and Lecture with Video + Demonstration + Interaction with successful farmers and their experience sharing during field visit (TM3) had convinced the Cashewnut growers evenly about the Cashewnut technologies for which they were exposed to. The Demonstration, Video and interaction with successful farmers were found to be effective methods for convincing the farmers and accepting technology mentally because of the principle applied i.e., 'Learning by doing' and 'Seeing is believing' in the above two methods. This findings is in line with the findings of Srishkumar (1979) [6] and Sadaqath (1986) ${ }^{[5]}$ Karthikeyan (1997) ${ }^{[3]}$ and Sriram (2000) ${ }^{\text {[7] who }}$ indicated that use of various extension methods influenced symbolic adoption behaviour of the fanners. Finally it would be concluded from the results that the treatment TM3 and TM2 were found to effective training methods in respect of its effectiveness in terms of symbolic adoption behaviour among the cashewnut growers.

\section{Developed Training Module for Sustainable Cashewnut Cultivation}

The effective Training module include various dimensions of training preferred by the respondents. Majority of the Cashewnut farmers preferred the training programme on cashewnut cultivation to be conducted by successful cashewnut farmers/Horticulture Scientist /officers, and preferred to get trained in groups. Institutional type of training conducted through lecture with video, demonstration and field visit at Krishi Vigyan Kendra during November - December for duration of one day was preferred by most of the respondents. Based on the present study, the Treatment 3 (TM 3) namely Lecture with Video + Demonstration + Interaction with successful farmers and their experience sharing during field visit was found to be effective interms of knowledge gain and symbolic adoption behaviour among the respondents of cashewnut cultivation. Technologies like planting, manures and fertilizers, intercultivation, training and pruning, plant protection, harvesting, value addition and by products on cashewnut cultivation were preferred by the respondents. So in future, the above developed module may be followed in all the area with slight adjustment according to the situation and type of respondents.

\section{Conclusions}

It could be concluded that Cashewnut is one of the cash crop among the commercial crops in India. To increase the export and income of the farmers, India has to increase production and productivity in cashewnut cultivation in order to meet out the sustainability/increase livelihood of the farmers and foreign needs. In order to increase the above set goals, extension agencies have to increase the farmer's knowledge and adoption behaviour of cashewnut through effective training module. In this study, the proven training module has developed to disseminate the technologies for sustainable cashewnut cultivation. So, the developed training module may be followed by all the extension agencies in our country for sustainable cashewnut cultivation.

\section{References}

1. Department of Horticulture and Plantation, Chennai, 2017. 
2. FAO. Food and Agricultural Organization of the United Nations. Production Year Book. Rome, 2017.

3. Karthikeyan C. An Experimental Study to Develop an Effective Training Module for Potential Growers of Export-oriented Cut flower. Unpub. Ph.D. Thesis, TNAU, Coimbatore, 1997.

4. Loganathan R, Chandrasekaran M. Agribusiness potential Impact of Horticulture Crops: An Agricultural Economic Analysis of Cashew Nut in Tamil Nadu. 2013; 3(12).

5. Sadaqath Syed. Relative Effectiveness of Group Meeting Plus Flip Chart and Group Meeting Plus Specimen on Farmers Knowledge, Attitude of Symbolic Adoption of DH 8 Groundnut - A Field Experiment. Unpub. M.Sc.(Ag.) Thesis, UAS, Bangalore, 1986.

6. Srishkumar K. A Study on Evaluate the Relative Effectiveness of Media Combination on Dairy Farmers of Tumkur District - A Field Experiment. Unpub. M.Sc.(Ag.) Thesis, UAS, Bangalore, 1979.

7. Sriram N. Developing Standardised Extension Education Module for sustainable cotton cultivation. Unpub. Ph.D. Thesis, TNAU, Coimbatore, 2000. 